\title{
International Particle Physics Outreach Group: Reaching across the globe with science
}

\author{
Steven Goldfarb ${ }^{1, *}$ (On Behalf of the IPPOG Collaboration $\left.{ }^{\dagger}\right)$ \\ ${ }^{1}$ The University of Melbourne, Parkville VIC 3010, Australia
}

\begin{abstract}
The International Particle Physics Outreach Group (IPPOG) is a network of scientists, science educators and communication specialists working across the globe in informal science education and outreach for particle physics. The primary methodology adopted by IPPOG requires the direct involvement of scientists active in current research with education and communication specialists, in order to effectively develop and share best practices in public engagement. IPPOG member activities include the International Particle Physics Masterclasses, Global Cosmics, International Muon Week and International Cosmic Day organisation, and participation in activities ranging from public talks, festivals, exhibitions, teacher training, student competitions, and open days at local institutions. These independent activities, often carried out in a variety of languages to public with a variety of backgrounds, all serve to gain the public trust and to improve worldwide understanding and support of science. We present our vision of IPPOG as a strategic pillar of particle physics, fundamental research and evidence-based decision-making around the world.
\end{abstract}

\section{Introduction}

Particle physicists active in science education and public engagement currently enjoy a unique opportunity to reach broad worldwide audiences and to create an important and lasting impact on society. We participate in one of the most fascinating fields of science, one that lies at the very core of human understanding of our universe. It is not a hard sell. Anyone with a slight interest in science or even a vague curiosity of our existence cannot help but be fascinated by efforts to try to understand the workings behind the most basic building blocks of the universe.

Beyond the science, current efforts in particle physics also feature human themes that resonate globally. The hardware, electronics and computing challenges of our field are forever pushing limits and, in many cases, their solutions result in improvements to our daily lives. Equally important, the expertise needed to address these challenges goes beyond the capabilities of any one institution or nation. It requires a concerted world-wide effort, involving international teams of researchers, engineers and technicians working together, each bringing their own cultural backgrounds and points of view to the table.

This provides us with a golden opportunity both to teach the scientific process and to promote the values of international collaboration around the globe. Toward these goals, the endeavours of particle physics are a powerful catalyst to engage and interest the public. We,

\footnotetext{
* Corresponding author: steven.goldfarb@cern.ch

$\dagger$ (C)2020 CERN for the benefit of the IPPOG Collaboration. CC-BY-4.0 license.
} 
as scientists, educators and communicators can offer the public - especially younger generations - the tools they need to differentiate fact from fiction, a particularly important commodity, today. In fact, it is one of IPPOG's [1] primary missions to do exactly that.

Fortunately, after many years of hard work and dedication, education and outreach are being recognised within the field as important strategic elements in international research. Nearly all of the major particle physics conferences, including CHEP [2], ICHEP [3], LHCP [4], relevant meetings of the APS [5] and EPS [6], and several others, now host dedicated parallel sessions, poster sessions, and even plenary presentations on those topics. These opportunities, which have arisen over the past couple decades, help to raise the stature of science education and outreach and to increase participation.

Along with the recognition and increased effort comes the need for formalisation and the development of infrastructure for long-term coordinated planning and development. This is where IPPOG comes into play. In fact, worldwide coordination of particle physics outreach is exactly the charge the organisation was given in its original charter. Formal IPPOG membership [7] currently comprises scientists, educators and communication specialists from 26 countries, 5 experiments and CERN [8], as an international laboratory. But these numbers, which are on the rise, represent only a small fraction of the growing worldwide effort currently being organised through its major programmes.

In this document, we present a broad overview of the IPPOG collaboration. We describe its history and its current composition, in terms of expertise and global distribution, scientific diversity and expected growth in the coming years. We present IPPOG's major activities, including Particle Physics Masterclasses and Global Cosmics, as well as current efforts to reach out to the general public through activities and exhibitions at science and cultural festivals. Finally, we present our vision of scientific education and public engagement as strategic pillars to our field, providing support to plans outlined in the European Particle Physics Strategy Update [9] concerning the future of worldwide particle physics.

\section{IPPOG History}

\section{$2.1 \quad$ EPPOG}

The European Particle Physics Outreach Group (EPPOG) was formed in 1997 under the joint auspices of the European Committee for Future Accelerators (ECFA) [10] and the High Energy Particle Physics Board of the European Physical Society (EPS-HEPP) [11]. During the first EPPOG meeting, held in September, 1997, then CERN Director General Chris Llewellyn Smith stated "the particle physics community has a moral obligation to inform the public on its activities. To do this well, experiences must be shared among countries in view of the need to optimize the use of resources" [13]. The motivation for the formation of the group was thus to create a mechanism to define common priorities and collective decisionmaking regarding education and outreach efforts.

During the first meeting, the primary tasks of EPPOG were defined to include: providing a forum for the exchange of information on outreach activities, taking an inventory of materials currently in use for particle physics outreach, pooling resources, identifying media contacts and identifying other possible collaborating partners to strengthen efforts. The original group comprised one delegate from each CERN member state, one additional CERN and DESY member, a Chair and a Deputy Chair appointed by ECFA and EPS-HEPP, and associate members from within the community, currently active in public outreach and communication. The group agreed to meet twice a year, to exchange ideas and best practices in particle physics education and outreach, to define common activities, and to develop and share material supporting their activities. A listing of Chairs is presented in Table $\mathbf{1 .}$ 
Meetings are typically hosted by CERN once a year, then by one of the participating institutes at their university or associated laboratory. Agendas from these meetings, starting in November, 1999, can be viewed in the CERN Indico Projects/IPPOG/Collaboration Meetings area [14]. Content includes reports from member states and the participating laboratories, presentations of national and international projects, exhibitions and events, and discussion on future plans and projects. A variety of guest speakers have joined the meetings over the years, providing an important forum on developments and metrics in informal education, communication and public engagement. Several meetings were arranged to overlap with those of the European Particle Physics Communication Network (EPPCN), after it was formed in 2007 to coordinate communication activities of the CERN member states, concerning particle physics.

Table 1. EPPOG/IPPOG Chairs

\begin{tabular}{|l|l|}
\hline Term & Chair(s) \\
\hline $1997-2001$ & Frank Close, Oxford University, UK \\
\hline $2002-2008$ & Erik Johansson, University of Stockholm, Sweden \\
\hline $2009-2012$ & $\begin{array}{l}\text { David Barney, CERN } \\
\text { Michael Kobel, Technical University of Dresden, Germany }\end{array}$ \\
\hline $2013-2016$ & $\begin{array}{l}\text { Hans Peter Beck, University of Bern, Switzerland } \\
\text { Marjorie Bardeen, Fermi National Laboratory, USA }\end{array}$ \\
\hline $2017-2019$ & $\begin{array}{l}\text { Hans Peter Beck, University of Bern, Switzerland } \\
\text { Steven Goldfarb, University of Melbourne, Australia }\end{array}$ \\
\hline $2020-2022$ & $\begin{array}{l}\text { Pedro Abreu, University of Lisbon, Portugal } \\
\text { Steven Goldfarb, University of Melbourne, Australia }\end{array}$ \\
\hline
\end{tabular}

\section{$2.2 \quad$ IPPOG}

As data-taking ramped up for the Large Hadron Collider (LHC) [17] experiments, so did EPPOG interest to include the participation of countries involved in the collaborations, but not member states to CERN. The experiments had become members of EPPOG, but not the countries. In a presentation during the October, 2010 EPPOG meeting, Chairs David Barney and Michael Kobel noted that there were more than "40 non-member and observer states of CERN, some of which [had] well-advanced outreach programs." In addition, other laboratories, such as KEK in Japan [18] and FNAL in the USA [19], were considered as potential new contributors to the group. Following agreement by the EPPOG collaboration board and subsequent approval by ECFA in November, 2010, EPPOG evolved to IPPOG, the International Particle Physics Outreach Group.

The first new member of IPPOG was the USA in 2012, represented by Marjorie Bardeen of FNAL, who went on to serve as IPPOG chair. Members joining in the following few years included Israel, Ireland, Slovenia, Australia and South Africa. These new members were each asked to make a presentation during an IPPOG meeting on their current activities in education and outreach and on their planned contributions to the IPPOG programme in future years. Current members then voted on their membership. Although only a majority of votes in favour were required, all of these new members were accepted by complete consensus. The group began to grow in earnest and the breadth and reach of activities expanded every year.

\subsection{The IPPOG Collaboration}

With expansion came an increased need for core infrastructure and official recognition of IPPOG worldwide activities. Resources to support the primary programmes, such as 
International Masterclasses, had been generously provided by CERN, through an agreement between the Director General and the University of Dresden, and by the University of Notre Dame, through an agreement with QuarkNet [20] in the USA. These agreements, however, needed periodic renewal and were not based on official recognition of IPPOG as a collaboration. Furthermore, additional funds were needed to maintain and develop core infrastructure, such as the web pages and resource database. CERN committed a fraction of an employee's time each year to provide secretarial duties, but more help was needed, due to the growth of the programmes, both in complexity and geographical spread.

With these issues in mind, IPPOG chairs Hans Peter Beck and Marjorie Bardeen began discussions with the group's members, the CERN Director General, CERN Council and ECFA on how best to pursue becoming an official international collaboration. By 2015, with the help of the CERN legal office, an official Memorandum of Understanding (MoU) was drafted, defining the structure, terms of membership and operation of the collaboration.

The MoU, which became valid in December, 2016, with the $10^{\text {th }}$ new member signature, specifies an agreement between IPPOG and the national bodies representing the member countries, collaborations and international laboratories. A national body is a scientific laboratory, institution or ministry, that has the right to participate on behalf of all particle physics bodies in the country. In brief, the MoU asks the member to recognise and support particle physics outreach and education in that country, to actively contribute to the IPPOG programmes, to appoint a representative to attend collaboration meetings and contributes a small monetary contribution to help support the core infrastructure. An international collaboration agrees to recognise and support efforts in education and outreach within the collaboration, provides access to data, tools and expertise for IPPOG activities, and also appoints an official representative. No funds are requested from collaborations, in order to avoid double counting by nations that are members of both the collaboration and IPPOG. Finally, international laboratories are negotiated on a case-by-case basis, with agreements written up in the form of addenda to the MoU. CERN is currently the only one; it generously provides IPPOG with funding for administration $(0.5 \mathrm{FTE})$ and masterclass coordination $(0.5$ FTE), as well as a monetary contribution and access to CERN legal and financial services. National laboratories and other scientific bodies, such as DESY and Centro Fermi, have the right to join IPPOG as associate members, allowing for participation in the Collaboration Board, but without a vote, as that is reserved for the single national representative body.

There are currently 33 IPPOG members: 26 countries, 6 international collaborations and 1 international laboratory. Of the original members, all but 3 have successfully identified the organisational bodies within their countries to sign the new MoU and commit to annual payments. The remaining countries continue to participate actively and will regain their voting rights, once their bodies have signed. Concurrently, several new countries and international collaborations have expressed interest and have either signed (e.g. Montenegro and HAWC [21]) or are pursuing the correct channels for signing in the near future. IPPOG has thus evolved into an increasingly sustainable international collaboration with a growing membership and a modest budget for the development of the core infrastructure needed to support major worldwide programmes in education and outreach.

\section{Programmes and Activities}

\subsection{Particle Physics Masterclasses}

A Masterclass differs from a typical class, as it is taught by an expert in the field, who is not necessarily a professional educator. The term is often associated with those taught by great musicians, in which they gave short demonstrations of a musical work and then listened to and provided advice and encouragement to students performing the same piece. The 
advantage of such, typically short, classes is that students take a break from their usual routine to learn and be inspired by experts and role models in their speciality. They gain hands-on experience and attain a more realistic perspective of what they need to do to succeed.

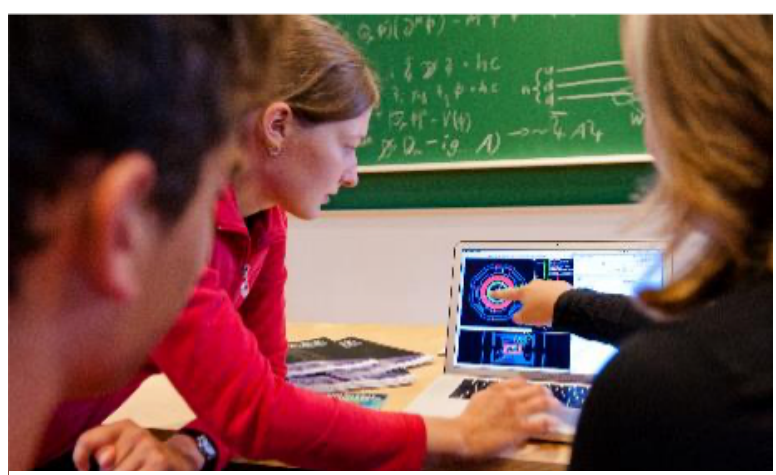

Figure 1. Particle physics masterclass

Similarly, particle physics masterclasses are typically run by scientists active in current research to classes of secondary students, outside of their usual lessons. The students get a chance to work with current tools on real data from active experiments, and have a chance to engage in conversation with experts in the field. They learn, in essence, what it is like to be a particle physicist, if only for a day, but the influence can be both immediate and long-lasting.

In a 2005 CERN Bulletin article [22], former IPPOG chair Michael Kobel, described the evolution of the particle physics masterclasses, believed to have their origin in the UK in 1997 by Ken Long of Imperial College and Roger Barlow of the University of Manchester. At the time, the masterclasses featured presentations and hands-on demonstrations using event-display software from the Large Electron-Positron (LEP) [23] collider experiments at CERN. In the years that followed, particle physics masterclasses grew in popularity across the UK and began to spread to other European countries, including Belgium, Germany and Poland.

\subsection{The International Particle Physics Masterclass Programme}

The idea of organising a world-wide programme of particle physics masterclasses was put forward by Michael Kobel during the October, 2003 EPPOG meeting. The programme would be hosted at universities and research centres around Europe, inviting local classrooms to participate. The morning agenda featured presentations and demonstrations about the LEP experiments, and also about local activities at the host institute. The afternoon agenda included a masterclass on measuring $\mathrm{Z}$ branching ratios at LEP, as well as other hands-on exercises, including cosmic ray measurements. The day concluded with a video conference joining classrooms who had taken part in the programme, so the students and mentors could share and discuss their results.

The proposal was enthusiastically embraced by EPPOG members, during and following the meeting, and dates were set up for the event. By March, 2005, particle physics masterclass learning packages had been developed and translated into 16 different languages. These were used in conjunction with the event visualisation tools provided by the participating experiments. CERN organised video conferencing connections for the schools and helped to operate and moderate the end-of-day wrap up sessions. These sessions instilled students with an appreciation for international collaboration, and provided then with a much stronger understanding of the scientific process, and how it is used in modern research.

The 2005 version of International Masterclasses (IMC) featured 3000 students in 72 classes held in 58 institutes across 18 countries, primarily in Europe. Since that time, IMC has truly become the flagship programme of IPPOG, and is reaching students in all populated continents around the globe. In 2019, IMC was held from 7 March to 16 April, and included the participation of over 10,000 high school students in 332 classes at 239 institutions in 54 
countries. The content has evolved and grown in physics scope, as well, featuring authentic data from the four major LHC experiments and a neutrino experiment in FNAL. Plans for 2020 included the addition of material from the Belle II experiment at KEK [24] and new masterclasses featuring data from several other experiments are being prepared for the future.

A more complete overview of the IPPOG IMC programme has been written up for these proceedings by F. Ould-Saada, of the University of Oslo, Norway, on behalf of IPPOG [25]. This includes details of the 2019 programme, as well as plans for the future, including the new masterclasses on Belle II data, Particle Therapy and Neutrino data from MicroBooNE. The proceedings also include descriptions of the usage of IMC for World Wide Data Day (W2D2) [26] and for the United Nations International Day of Women and Girls in Science (IDWGS) [27]. A detailed description of the new package integrating all ALICE Masterclass exercises, as well as a Particle Therapy Masterclass, has been written up for these proceedings by L. Graczykowski, P. Nowakowski and P. Foka, also on behalf of the IPPOG collaboration [28].

\subsection{The Global Cosmics Programme}

Much of our early understanding of high-energy fundamental particle physics came from the study of cosmic rays [29]. The subsequent discoveries of massive fundamental particles outside of the lighter, stable collection in the existing models motivated physicists to develop accelerators and detectors, eventually leading to the large-scale programmes that define the field today.

Fortunately, construction and operation of the instruments needed to detect and make simple measurements of cosmic rays are straightforward and inexpensive, making them excellent tools for the classroom. Students learn basic particle physics concepts and methods, while learning how to set up experiments, operate hardware, take data and perform analysis. As a result, cosmic ray experiments, employing a variety of detector types, have been installed in classrooms around the world. Many of these have been connected together into networks, allowing students to share data and to produce scientific results in a manner similar to our much larger-scale international collaborations.

In order to better exploit the great potential of cosmic-ray experiments for particle physics outreach, IPPOG launched an effort to create a common umbrella for these globally separate programmes. A workshop was organised in Rome in 2017 bringing together experts from a global spectrum of cosmic-ray related educational activities. It was agreed at that meeting to create an IPPOG Global Cosmics working group, the goal of which is to develop and promote worldwide activities, connecting classrooms through their cosmic ray studies. Current global activities include International Cosmic Day (ICD), organised by DESY, and Muon Week, organised by QuarkNet. Both events are promoted and supported by IPPOG and its members.

\subsection{Public Events and Cultural Festivals}

Outside of the classroom, IPPOG members are active in public engagement, giving talks at various events, from science festivals to film screenings, open days, pubs, cafes, libraries, and more. The originality and quality of the talks, exhibitions, and demonstrations prepared by the researchers are quite impressive, and these novel ideas are often shared during IPPOG meetings. Dedicated working groups, such as "Exhibits \& Exhibitions" or "Explaining Particle Physics Hot Topics to a Lay Audience" provide forums for discussion and the development of material and best practices.

More recently, modest core funding has been allocated to support efforts to reach new audiences through creative methods and unusual venues. While the majority of support comes through institutional funding or in-kind contributions by the members, IPPOG funds 
can be used to help with needed infrastructure, material, printing costs, or limited travel money for visits by local scientists or students who would not normally have that support.

A recent competition held by IPPOG to encourage young girls and women to consider careers in science "Girls, Do Physics," [32] for example, awarded a classroom in Iran with a visit from a local scientist engaged in LHC research. Support was also provided for material for scientists hosting talks, demonstrations and exhibitions at the WOMAD Festival [33] in the UK, the Colours of Ostrava festival [34] in the Czech Republic, the Pohoda Festival [35] in Slovakia and the Universal Science [36] public event held in Adelaide,

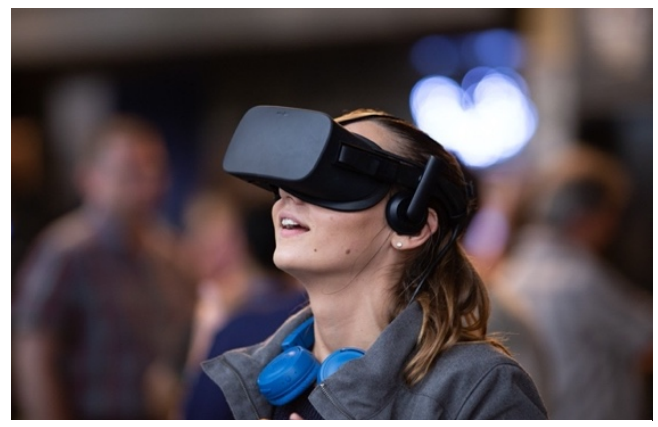

Figure 2. Engagement at cultural festivals Australia, as part of CHEP 2019. Activities at non-science festivals are successful in reaching new audiences and members of the public who had not yet realised their appreciation for research. In addition, events held adjacent to major physics conferences reach our own colleagues, as well as the public, encouraging the two groups to interact and improving their exposure to IPPOG and its outreach programmes.

\section{Summary and Future Outlook}

The International Particle Physics Outreach Group is an international collaboration of researchers, science communicators, and educators committed to the creation, development and operation of high-quality activities and material for scientific outreach on a global scale. IPPOG activities, such as International Particle Physics Masterclasses and the annual Global Cosmics events, reach tens of thousands of students in classrooms located in countries around the world, with the geographical reach growing every year. A broadening of the scope of physics topics covered in these activities is strengthened through partnerships with the Astroparticle Physics European Consortium (APPEC) [37], the Nuclear Physics European Collaboration Committee (NuPECC) [38], the newly-formed International Gravitational Waves Outreach Group (IGRAV) [39] and a widening of membership to include countries, experiments and laboratories active in diverse research programmes.

One of the most important and visible impacts of IPPOG is growing recognition within the particle physics community of education and outreach as key strategic elements of largescale international research. Such efforts are no longer considered as extraneous activities, to be carried out in our spare time at the completion of research, but rather as essential to our ability to effectively carry it out. When the European Particle Physics Strategy Update is completed in 2020, it will call on international laboratories and scientific collaborations to develop accelerators and experiments larger, costlier and more complex than ever before conceived. To achieve such a grand vision, it is essential to establish firm support with governments, the voting public and the younger generations that will eventually contribute to and carry out the research.

IPPOG has already begun this work. Through its extensive programmes of education and public engagement, IPPOG not only offers the world clear descriptions of this new and exciting research, but it instils young minds with a better understanding of the scientific method and a deep appreciation of evidence-based decision making. This is essential today, in a world, in which these essential human values are continually under attack by public figures in politics and the media; the repercussions of this work go far beyond that of supporting and popularising our field. In the coming years, IPPOG will continue to grow and 
improve its capabilities, through increased worldwide membership, a richer palette of physics topics, and a broadened global reach of its education and outreach programmes.

\section{References}

[1] International Particle Physics Outreach Group: https://ippog.org.

[2] International Conference on Computing in High Energy \& Nuclear Physics: http://chep2019.org.

[3] International Conference on High Energy Physics: https://ichep2020.org.

[4] Conference on Large Hadron Collider Physics: http://www.lhcp2020.fr.

[5] American Physical Society: https://aps.org.

[6] European Physical Society: https://eps.org.

[7] IPPOG Membership: http://ippog.org/ippog membership.

[8] European Organization for Nuclear Research: http://home.cern.

[9] European Particle Physics Strategy Update 2020: https://europeanstrategyupdate.web.cern.ch.

[10] European Committee for Future Accelerators: https://ecfa.web.cern.ch.

[11] European Physical Society - High Energy Particle Physics Board: https://epshepp.web.cern.ch.

[12] E. Johansson, CERN Courier, vol. 44, issue 3, p 42: http://cds.cern.ch/record/1733613.

[13] Minutes of the First Meeting of the Network on Public Relations and explaining Particle Physics to the public in the CERN Member States, Sep. 1997: http://outreachold.web.cern.ch/outreach-old/public/Minutes/970919.html.

[14] Minutes of all EPPOG/IPPOG Meetings from November, 1999: https://indico.cern.ch/category/9657.

[15] Minutes of the 27th Meeting of the European Particle Physics Outreach Group: https://indico.cern.ch/event/107976.

[16] European Particle Physics Communication Network: https://espace.cern.ch/EPPCNsite/ layouts/15/start.aspx\#/EPPCN\%20Web\%20Page/Home.aspx.

[17] Large Hadron Collider at CERN: https://home.cern/science/accelerators/large-hadroncollider.

[18] High Energy Accelerator Research Organization (KEK): https://www.kek.jp.

[19] Fermi National Accelerator Laboratory (FNAL): https://www.fnal.gov.

[20] QuarkNet is an NSF-funded partnership between FNAL and the University of Notre Dame supporting particle physics education and outreach: https://quarknet.org.

[21] High-Altitude Water Cerenkov Gamma-Ray Observatory: https://www.hawcobservatory.org.

[22] "Masterclass spreads the word for physics," M. Kobel, CERN Courier, 28 Sep 2005: https://cerncourier.com/a/masterclass-spreads-the-word-for-physics.

[23] Large Electron-Positron Collider at CERN: https://home.cern/science/accelerators/large-electron-positron-collider.

[24] Belle II Experiment: https://www.belle2.org.

[25] F. Ould-Saada, "International Particle Physics Masterclasses Current development to expand scope and global reach," these proceedings.

[26] World Wide Data Day: https://quarknet.org/content/world-wide-data-day.

[27] United Nations General Assembly Resolution adopted on 22 December 2015: https://www.un.org/en/ga/search/view doc.asp?symbol=A/RES/70/212.

[28] L. Graczykowski, P. Nowakowski and P. Foka, "New developments for ALICE MasterClasses and the new Particle Therapy MasterClass," these proceedings.

[29] D. Pacini (1912). "La radiazione penetrante alla superficie ed in seno alle acque". Il Nuovo Cimento. 3 (1): 93-100: https://arxiv.org/abs/1002.1810. 
[30] International Cosmic Day, DESY: https://icd.desy.de.

[31] International Muon Week, QuarkNet: https://quarknet.org/content/international-muonweek.

[32] Girls, Do Physics: https://ippogorg.wixsite.com/girlsdophysics.

[33] WOMAD Festival: https://womad.co.uk.

[34] Colours of Ostrava: https://www.colours.cz.

[35] Pohoda Festival: https://www.pohodafestival.sk/en.

[36] Universal Science: https://universalscience.web.cern.ch.

[37] Astroparticle Physics European Consortium: https://www.appec.org.

[38] Nuclear Physics European Collaboration Committee: http://www.nupecc.org.

[39] 1st Meeting of the International Gravitational Waves Outreach Group: https://indico.ego-gw.it/event/29. 